\title{
New Processes for Cleaning Gas Emissions from Nitrogen Oxides
}

\author{
Yurii Beznosyk $^{1}$, Liudmyla Bugaeva ${ }^{2}$
}

1. The Department of Cybernetics of Chemical Technology Processes, National Technical University of Ukraine "Igor Sikorsky Kyiv Polytechnic Institute”, UKRAINE, Kyiv, 37 Peremohy Ave, E-mail yu_beznosyk@ukr.net

2. The Department of Cybernetics of Chemical Technology Processes, National Technical University of Ukraine "Igor Sikorsky Kyiv Polytechnic Institute", UKRAINE, Kyiv, 37 Peremohy Ave, E-mail bugaeva_1@ukr.net

Abstract - The process of cleaning exhaust gases from nitrogen oxides with a solution of carbamide has been examined. Neutral nitrogen, carbon dioxide and ammonium nitrate solution as a fertilizer are formed as a result of the purification. The mechanism of reactive absorption of nitrogen oxides with a solution of carbamide is investigated. The effect of nitrogen oxides concentration, solution temperature, gas flow rate on the degree of purification is shown.

Keywords - simulation, gas purification, reactive absorption, nitrogen oxides, carbamide, absorption column.

\section{Introduction}

Among absorption-reduction methods of gas purification from nitrogen oxides, the method involving solution of carbamide is of primary interest. Using this absorbent, nitrogen oxides are deoxidised to ecologically safe elementary nitrogen. Ammonium salts are accumulated in the solution, and they are easily utilised as nitrogen-containing manures. The degree of absorption of nitrogen oxides by the carbamide absorbent at the single stage of absorption reaches $75-80 \%$. This allows synthesising the technological scheme of purification of industrial waste gases that ensures maximally allowable concentration of $\mathrm{NO}_{\mathrm{x}}$ in gas exhausts $[1,2]$.

\section{Absorption by carbamide}

Carbamide and its solution are highly perspective nitrogen oxide absorbent. When absorption by carbamide solution is used, non-toxic products, such as $\mathrm{N}_{2}, \mathrm{CO}_{2}, \mathrm{H}_{2} \mathrm{O}$, form. The study of the process of gas purification from nitrogen oxides by solutions of carbamide was fulfilled by means of the dynamic method in a glass column with irrigated walls.

To coat all surface of the pipe by a liquid film, the spraying density was at the level of $20 \mathrm{~m}^{3} /\left(\mathrm{m}^{2} \mathrm{hr}\right)$. The process was studied under the following technological conditions: nitrous gas oxidability of $20 \ldots 60 \mathrm{vol} \%$, air-gas stream linear velocity of $0.5 \ldots 2.5 \mathrm{~m} / \mathrm{s}$, carbamide concentration in absorber of $1 \ldots 10 \%$, carbamide solution temperature of $293 \ldots 333 \mathrm{~K}$, nitrous gas concentration of $0.03 \ldots 1.0 \mathrm{vol} \%$.

Based on the obtained results, the authors made a supposition that the process is described by the following total equation:

$$
\mathrm{NO}_{2}+\mathrm{NO}+2\left(\mathrm{NH}_{2}\right)_{2} \mathrm{CO}+2 \mathrm{HNO}_{3} \rightarrow 2 \mathrm{CO}_{2}+2 \mathrm{~N}_{2}+2 \mathrm{NH}_{4} \mathrm{NO}_{3}+\mathrm{H}_{2} \mathrm{O}
$$

The following stages of the process have been defined by means of the investigations on the process of reduction of nitrogen oxides by water solutions of carbamide:

Nitrogen oxides dissolve in water with formation of nitric and nitrous acids.

Nitric and nitrous acids react partially with carbamide:

$$
\left(\mathrm{NH}_{2}\right)_{2} \mathrm{CO}+\mathrm{HNO}_{3}+\mathrm{HNO}_{2} \rightleftarrows \mathrm{NH}_{4} \mathrm{NO}_{3}+\mathrm{N}_{2}+\mathrm{CO}_{2}+\mathrm{H}_{2} \mathrm{O}
$$

The supposed mechanism is as follows:

$$
\begin{aligned}
\mathrm{HNO}_{2}+\mathrm{H}^{+} & \rightarrow \mathrm{NO}^{+}+\mathrm{H}_{2} \mathrm{O} \\
\left(\mathrm{NH}_{2}\right)_{2} \mathrm{CO}+\mathrm{NO}^{+} & \rightarrow \mathrm{CO}_{2}+\mathrm{N}_{2}+\mathrm{NH}_{4}^{+}
\end{aligned}
$$

The second stage is limiting. 
To determine the mass-transfer coefficients some experiments were conducted on a pilot plant of the waste gas treating for a glasswork. The column of $0.5 \mathrm{~m}$ in diameter consists of the water lock of $0.8 \mathrm{~m}$ in height, the layer of regular packing of $1.4 \mathrm{~m}$ in height. The gas linear velocity was held at the range from 0.4 up to $2.5 \mathrm{~m} / \mathrm{s}$, the spraying density - from 20 up to $40 \mathrm{~m}^{3} /\left(\mathrm{m}^{2} \mathrm{hr}\right)$. At the spraying density of $28.7 \mathrm{~m}^{3} /\left(\mathrm{m}^{2} \mathrm{hr}\right)$ under increase of the gas linear velocity from 0.47 up to $2.39 \mathrm{~m} / \mathrm{s}$ a mass-transfer coefficient of nitrogen oxides absorption by $2 \%$ carbamide solution changes in a range of $(1.01 \ldots 2.27) 10^{-10} \mathrm{~g} /\left(\mathrm{m}^{2} \mathrm{~s} \mathrm{~Pa}\right)$.

Nitrous gases with the oxidation degree less than 50\% should be acidified, or it is necessary to use absorbents with a supplement of reagents, which are able to oxidise $\mathrm{NO}$ to $\mathrm{NO}_{2}$. Such reagents are $\mathrm{H}_{2} \mathrm{O}_{2}, \mathrm{KClO}_{4}, \mathrm{KMnO}_{4}$.

\section{Conclusion}

The obtained outcomes on the $\mathrm{NO}_{\mathrm{x}}$ recovery degree dependence on nitrous gas oxidability at the gas linear velocity of $0.5 \mathrm{~m} / \mathrm{s}$, the spraying density of $20 \mathrm{~m}^{3} /\left(\mathrm{m}^{2} \mathrm{hr}\right)$ and $5 \%$ carbamide concentration in absorbing solution demonstrate that when oxidability increases from 10 up to $65 \%$, the recovery degree raises from 14.2 up to $53 \%$.

The absorbent temperature increase (under the same absorption conditions) results in the decrease of $\mathrm{NO}_{\mathrm{x}}$ recovery degree from $50 \%$ at $283 \mathrm{~K}$ up to $14.5 \%$ at $343 \mathrm{~K}$.

When the carbamide concentration increases from 1 up to $2 \%$, the $\mathrm{NO}_{\mathrm{x}}$ recovery degree grows from 38.2 up to $45.5 \%$. More than $2 \%$ carbamide concentration in the absorbing solution practically does not influence on the recovery degree. For example, the absorption by 5\% solution of carbamide augments the recovery degree up to $48.5 \%$ only.

The increase of the gas velocity from 0.1 up to $2.5 \mathrm{~m} / \mathrm{s}$ augments the degree of $\mathrm{NO}_{\mathrm{x}}$ recovery from 28 up to $76 \%$.

It was determined that the degree of $\mathrm{NO}_{\mathrm{x}}$ recovery depends on their concentration in a gas a little. The influencing is essential at very low $\mathrm{NO}_{\mathrm{x}}$ concentrations only. So at $1 \mathrm{vol} \%$ of $\mathrm{NO}_{\mathrm{x}}$ concentration the degree of recovery makes $85 \%$, and at 0.039 vol\% reduces up to $73 \%$ (under the same conditions of the process).

It is evidenced that the basic resistance of mass transfer is focused in a gas phase at the low concentrations.

The analysis of the outcomes shows that as the gas mixture linear velocity increases from 1.0 to $2.5 \mathrm{~m} / \mathrm{s}$, the NOx reduction degree rises appreciably up to $80 \%$ (what allows reaching the required standards for the maximum allowed exhausts of NO for steam power plants $200 \mathrm{mg} / \mathrm{m} 3$ ). The further rise of the gas linear velocity (more than $2.5 \mathrm{~m} / \mathrm{s}$ ), under the same optimum technological parameters of the process, increases a mass-transfer coefficient slightly up to $82 \ldots 84 \%$. The needed increase of a gas-air flow linear velocity is limited by both large volumes of power plant exhaust gases and flooding of a column.

\section{References}

[1] L. N. Bugaeva, T. V. Bojko, and Yu. A. Beznosik, System analysis of chemicaltechnological systems, Kyiv: Interservice, 2017.

[2] L. N. Bugaeva, Yu. A. Beznosik, G. A. Statjukha, and A. A. Kvitka, "An application of expert system to choice, simulation and development of gases purification processes," Journal Computers \& Chemical Engineering, Vol. 20, Suppl., pp. S402-S406, 1996. 